\title{
Signs and Symptoms of Reported Cases of Transfusion Reactions in a Rural University Teaching Hospital, Niger-Delta Region of Nigeria
}

\author{
*Dr. Nwagu, Marcellinus Uchechukwu ${ }^{1}$, Dr. Borke Moghene Emona ${ }^{2,}$ \\ Dr. Awunor Nyemike Simeon ${ }^{3}$ \\ ${ }^{I}$ Senior lecturer/Consultant Haematologist Department of Haematology and Blood Transfusion, \\ Faculty of Clinical Medicine, Delta State University, Abraka, Delta State, Nigeria \\ ${ }^{2}$ Department of Haematology and Blood Transfusion, Senior Lecturer/Consultant Haematologist Faculty of \\ Clinical Medicine, Delta State University, Abraka, Delta State, Nigeria \\ ${ }^{3}$ Department of Community Medicine, Lecturer/Consultant Community Health Physician Faculty of Clinical \\ Medicine Delta State University, Abraka
}

\begin{abstract}
Background: Blood and blood components transfusion is a very important component of medical practice and patients'care. However, this wonderful therapeutic tool is associated with some disadvantages namely adverse transfusion reactions which in some cases lead to fatal consequences defeating the essence of its usage.

Objectives: This study aims to establish the modes of presentations (signs and symptoms) of blood transfusion reactions among recipients of blood in Delsuth, Oghara.

Methodology: Records of our patients who were reported to have blood transfusion reactions for a two-year period (July 2014-June 2016) were retrieved and studied. Data obtained were analysed using SPSS version 22.

Results: The incidence of adverse transfusion reaction was $0.86 \%$. The youngest subject was 2years while the oldest was $70 y e a r s$. The mean age was $38.69 \pm 14.95 y$ ears while the median age was 40years. The females were more than the males, $76.1 \%$ and $23.9 \%$, respectively. Whole blood transfusion was $93.5 \%$ while packed red blood cells was $6.5 \%$. Chills/rigors (63\%) was the leading symptom of presentation followed by fever/pyrexia (58.7\%). Itching/urticaria was $30.4 \%$ whereas nausea/vomiting was $19.6 \%$. Hypotension (6.5\%), tachypnea (4.3\%) and tachycardia(2.2\%) were the clinical signs. About forty- five percent of the transfusion reactions came from $O \& G$ department followed by Surgery department (21.7\%), Internal Medicine (17.4\%), Paediatrics(8.7\%) and $A \& E(6.5 \%)$. Almost seventy percent (67.4\%) of the patients were of blood group $O$ $+v e$.

Conclusion/Recommendations: Incidence of transfusion reaction in Delsuth is high. More of adverse transfusion reactions occur at night. Transfusion of whole blood should be discouraged together with transfusing a patient at night (except in emergency). Further research is advocated to determine why more transfusion reactions occur at night.
\end{abstract}

Keywords: Signs Symptoms Transfusion Reactions Niger-Delta Nigeria

\section{Introduction}

There has been a remarkable positive changes and improvement in transfusion practice since its introduction in healthcare delivery system. Blood transfusion has now become an indispensable tool in clinical practice for total care of patients. The first attempted blood transfusion was in the $17^{\text {th }}$ century and it involved transfusion of animal blood to human beings with its deleterious consequences. This animal to human blood transfusion continued till $19^{\text {th }}$ century ${ }^{1}$. Even though James Bunnel was credited to have successfully carried out first human to human blood transfusion in 1819, John Henry Leacock had earlier confirmed experimentally in 1816, using cats and dogs, that both the blood donor and the recipient must be of the same specie. He made this conclusion in Edinburgh in $1816^{1}$. Not until about 100years later when Karl Landsterner developed the ABO blood group system, blood transfusion had been associated with lots of morbidity and mortality. The knowledge about the $\mathrm{ABO}$ blood groups has made blood transfusion practicable routinely. However, due to the occurrence of complications, adverse reactions and complaints following blood transfusion, the issue of safety has been a big burden and concern to transfusionists and healthcare providers. Complications of blood transfusion include haemolytic transfusion reactions, circulatory and iron overloads, transmission of infectious agents such as bacteria, viruses (e.g hepatitis, and HIV, CMV) and febrile non-hemolytic reactions. Haemolytic transfusion reactions have immunological basis where the recipient develops antibodies/complement against the 
donor blood antigens. There is no other visible explanation to this except that the patient received a unit of blood or its product ${ }^{2,3}$. Febrile transfusion reactions can be haemolytic (FHTR) or non-hemolytic transfusion reaction (FNHTR) and is defined as a rise in temperature of $1^{0} \mathrm{C}$ or more associated with blood transfusion in the absence of other causes of fever. Febrile reactions are believed to be the commonest transfusion reaction ${ }^{4}$.

This reaction may occur during the transfusion or within 1-2hrs after the transfusion. The allergic transfusion reactions and urticarial reactions have also been reported $^{5-6}$.

Haemolytic transfusion reactions can either be immediate or delayed depending on the time of onset of clinical features and presentations. Immediate transfusion reactions occurs within 24hours of transfusion and it occurs as a result of clerical errors or administrative mistakes. It is usually due to ABO incompatibility and fortunately very much avoidable. This type of reaction is known and believed to be the most dangerous transfusion reaction and the offending antibodies are usually complement-activating $\operatorname{IgM}$ or $\operatorname{IgG}^{3}$. However, in the case of delayed transfusion reaction the signs and symptoms develop more than $24 \mathrm{hrs}$ after the transfusion. In most cases, the only sign of transfusion reaction is a progressive unexplained anaemia in the presence or absence of jaundice. In some cases where the offending antibody is not detected at crossmatch (due to the low titre of such immunoglobulins), following re- immunization with transfusion of incompatible red cells such antibodies lead to delayed transfusion reaction with increased clearance of red cells, anaemia and jaundice. Delayed transfusion reaction is most often caused by anti-c or anti-JK antibodies ${ }^{7}$. There have been cases where transfused red blood cells are destroyed without any detectable antibodies ${ }^{8,9}$. Even autologous blood transfusion (self blood transfusion) is associated with one form of adverse transfusion reaction or the other ${ }^{10}$. Apart from the aforementioned, post-transfusion purpura and Transfusion Related Acute Lung Injury(TRALI) are other important adverse transfusion reactions.

There is paucity of data on adverse transfusion reactions in Nigeria especially in Niger-Delta region of Southern Nigeria. The few reports available showed a varied prevalence of transfusion reactions. A recent study carried out in Zimbabwe reported a prevalence of $0.046 \%{ }^{11}$ which was at variance with a Nigerian study by Arewa et al five years earlier which posted an over all prevalence of $8.7 \%^{12}$. The reactions from the Nigerian study were febrile reactions which constituted most of the reactions (65\%) while allergic reactions and haemolytic transfusion reactions made up the remaining proportions ${ }^{12}$

The system of Haemovigilance has been established worldwide to reduce the incidence of adverse transfusion reactions. This system ensures that all data relating to transfusion reactions on any transfusion is collated and analysed in view of coming up with policies and modalities at promoting the

haematological and immunological safety of blood and blood products ${ }^{13}$. The aim of this study is to evaluate all the reported clinical features and presentations (signs and symptoms) from patients who reacted to blood transfusions at Delta State University Teaching hospital, Oghara. The findings from this research would be the basis for establishment of Haemovigilance in the hospital.

\section{Methodology}

This study was carried out at the blood bank of Delta State University Teaching Hospital (DELSUTH), Oghara, Ethiope East Local Government area of Delta State, Niger-Delta region of Southern Nigeria. Delsuth is a relatively new tertiary healthcare facility commissioned in 2010 and provides specialised care for a large proportion of patients both in Delta state and other neighboring states such as Edo, Bayelsa, Anambra and Rivers States. This is a retrospective study involving all the reported blood transfusions reactions for two years, $1^{\text {st }}$ July 2014 to $30^{\text {th }}$ June, 2016. Each unit of blood given out for transfusion was accompanied by an Adverse Reaction Form(ARF). If there was any adverse reaction the transfusing physician would fill this form and return same immediately to the blood bank for appropriate investigations. On filling the form, the following information concerning the recipient were provided in each of the ARF: the age, gender/sex, component being transfused, complaints of the recipient, the ward, temperature and duration of the transfusion prior to the reaction. Other information provided include the recipient's blood group, period of the transfusion (morning/afternoon/night) and indication for the transfusion. The volume of blood transfused prior to transfusion reactions and whether or not there has been previous transfusion reactions should be provided. These ARFs for the two-year period were retrieved, the information collated and analysed.

Data analysis: The Data collated were analysed with computer and IBM SPSS version 22.0 software. Frequency distribution tables and bar charts were used for presentations of selected variables.

\section{Results}

A total of forty six (46) transfusion reactions were reported for the study period out of five thousand three hundred and forty-two $(5,342)$ transfusions carried out within the two-year period under study. This gave an incidence of $46 / 5342(0.86 \%)$. Among the 46 recipients who had transfusion reactions, the oldest was 
70years while the youngest was 2 years (see table I). The mean age was $38.69 \pm 14.95 y e a r s$ while the median age was 40years. Fig 1 showed the sex distribution of the subjects which indicated that 11/46(23.9\%) were males while 35/46(76.1\%) were females.

Fig. 2 showed the blood component received by the recipients, more than ninety percent were whole blood 43/46(93.5\%) while the remaining 3/46(6.5\%) were packed red blood cells. Table 2 shows the signs and symptoms presented by the recipients during the adverse transfusion reactions. Chills/rigors took the lead of the presenting symptoms accounting for 29/46(63\%). This is followed by fever/pyrexia presented by $27 / 46(58.7 \%)$ of the recipients. Fourteen of the recipients $\{14 / 46(30.4 \%)\}$ complained of itching/urticaria while 9/46(19.6\%) complained of nausea/vomiting. Other complaints were mainly pains which included pains at the site of transfusion 5/46(10.9\%), back pains 4/46(8.7\%) and chest pains 3/46(6.5\%). The clinical signs picked up when the recipients were examined were hypotension in 3/46(6.5\%) of the recipients while tachypnea and tachycardia were seen in $2 / 46(4.3 \%)$ and $1 / 46(2.2 \%)$, respectively.

Table 3 shows the distribution of adverse transfusion reactions from various departments and wards of the hospital. Transfusion reactions from the department of Obstetrics and Gynaecology (O \& G) were of the majority comprising of almost half of the recipients $21 / 46(45.7 \%)$. Surgery department was the next $10 / 46(21.7 \%)$ while the department of Internal medicine contributed $8 / 46(17.4 \%)$ of the transfusion reactions. Adverse reactions from the department of Paediatrics were 4/46(8.7\%) while 3/46(6.5\%) came from Accident and Emergency(A and E) wards.

The ABO and Rhesus Blood group of the recipients were shown in table 4. Close to seventy percent of the recipients $31 / 46(67.4 \%$ ) were of blood group O rhesus positive while $8 / 46(17.4 \%$ ) had blood group A rhesus positive. Two of the recipients $2 / 46(4.3 \%)$ had groups $\mathrm{O}$ negative, B negative and $\mathrm{AB}$ positive, respectively. Only one patient $1 / 46(2.2 \%)$ had blood group B rhesus positive.

\section{Discussion}

The incidence of adverse blood transfusion reaction at DELSUTH, Oghara from this study was $0.86 \%$ closely similar to to a study in Puerto Rico with incidence of $0.2 \%$. However, our incidence was eighteen times higher than the incidence recorded by a study in Zimbabwe ${ }^{11}$ of $0.046 \%$ and another study in South Africa ${ }^{15}$ with overall incidence of $0.049 \%$. This is because the Zimbabwe study was for a long period of twelve years where 308 transfusion adverse events were reported for 670,625 blood components distributed ${ }^{11}$. In addition, Zimbabwe distributed more of blood components, this could also be another reason they recorded low incidence unlike in our study where more than $90 \%$ of the recipients received whole blood. The latter contributed only $8.9 \%$ of components in the Zimbabwe study. This further adds credence that whole blood transfusion should be discouraged and component transfusion therapy promoted. Our incidence is lower than the value obtained from a similar study in Ile-Ife, Nigeria ${ }^{12}$ which had an incidence of $8.7 \%$, about ten times higher than our value. This can be explained by the fact that there is possibility of under-reporting the cases of adverse reactions we had at our centre within the study period. Especially when most of the transfusions took place at night ( see table

5). Our study showed that transfusion adverse reactions are more in females $(76.1 \%)$ than the males. This is similar to the study by Nyashadzaishe et al in Zimbabwe $^{11}$ where $61.6 \%$ of adverse reactions came from females. This reflects pattern of hospital admissions where it is believed the females are admitted in the hospital more than the males ${ }^{15}$. Again, at Delsuth Oghara more female patients are admitted to the hospital because they hope to benefit from the free maternal \& child health care being provided by the Delta state government.

Blood transfusion reactions from our studies occurs across all age groups even at extremes of life (2years-70years) which is also similar to previous studies (1-89years) ${ }^{11}$. Whole blood transfusion in this study was $93.5 \%$ while packed red blood cells made up the remaining 6.5\%. As earlier mentioned, this was attributable to one of the reasons we had a higher incidence of adverse reactions when compared to a previous study. Whole blood transfusion is associated with blood transfusion reactions more than blood components because of numerous antigens being exposed to the recipient of whole blood. Most clinical situations require the use of specific blood components and the use of whole blood is quite rare in most developed countries. ${ }^{17}$ Therefore it is advocated and recommended that facilities should be put in place for the production of blood components in the hospital. Chills/rigors and fever/pyrexia were the common presenting symptoms of the recipients. These symptoms were indicative of mainly febrile non-hemolytic transfusion reaction (FNHTR) which were also the common adverse reactions recorded by Arewa et al in Ile Ife ${ }^{12}$ and Nyashadzaishe et al in Zimbabwe il. $^{11}$

Fever/pyrexia was $58.7 \%$ in our study almost the same with Zimbabwe study which recorded $58.5 \%$. FNHTR is the commonest adverse transfusion reactions ${ }^{3}$ and the fever is caused by action of cytokines e.g IL$1, \mathrm{IL}-6$, on the thermoregulatory centre of the anterior hypothalamus leading to production of Prostaglandin $\mathrm{E}_{2}{ }^{17}$. Studies have shown that accumulation of these cytokines in the stored blood lead to febrile adverse reactions. FNHTR is of great clinical importance because its occurrence often leads to discontinuation of blood transfusion and wastage of blood and blood products which atimes are not available. Itching/urticaria was $30.4 \%$ indicative 
of allergic transfusion reactions. This was similar to that of previous studies of $31.6 \%{ }^{11}$ and $32,5 \%^{12}$ and $30.6 \%{ }^{18}$ of minor allergic transfusion reactions. This was due to antibody response to plasma proteins in the donor's plasma ${ }^{19,20}$. hence allergic transfusion reaction is more common with plasma transfusion than red cell transfusion ${ }^{21}$. The use of specific component transfusion instead of whole blood will reduce the incidence of allergic transfusion adverse reactions. Complaints of pain was another important symptom from this study making a total of $26.1 \%$ of the signs and symptoms. These pains included pain at site of infusion (10.9\%), back pains $(8.7 \%)$ and chest pains $(6.5 \%)$. It has been noted that recipients can have any of these pains as a result of blood transfusion especially in cases of acute haemolytic transfusion reactions, characterized by flank pains, chest pains, hemoglobinemia and hemoglobinuria. It is possible our recipients had acute haemolytic transfusion reactions (AHTR), however, there were no other features of AHTR such as passage of coca-colored urine and clinical jaundice. Further laboratory tests performed in support of hemolysis and AHTR were negative e.g direct anti-human globulin tests. However, this does not completely rule out haemolytic reactions because there have been reported cases in which transfused red cells are quickly destroyed without detectable blood group antibodies $^{8,9}$.

Our study showed that the commonest sign on examination of these recipients was hypotension which was recorded in $6.5 \%$ of the recipients. A Hypotensive transfusion reaction (HTR) is rare and it occurs when low blood pressure is recorded following the administration of blood products. The hypotension quickly resolves on stoppage of the transfusion. The low blood pressures are caused due to the production of bradykinin which are produced through contact factor (Factor XII) activation. This activation of Factor XII is by negatively charged surfaces such as filters. When mechanisms for the degradation of bradykinin are impaired, the peptide builds up and causes hypotension (low blood pressure) ${ }^{22}$.

Looking at the various departments and wards, the adverse transfusion reactions from departments of Obstetrics/Gynaecology and Surgery are more than that of departments of Internal medicine and Paediatrics. These observations can easily be explained by the fact that the operative departments usually make demands and requests of blood and blood products more than the departments not associated with various surgical procedures. During surgical operations which is common in these two departments significant loss of blood are recorded necessitating blood transfusion. In addition, loss of blood is associated with deliveries especially in post partum haemorrhages, misscariages, placenta abruptio/previea and other obstetrics complications. Annually, a massive obstetric haemorrhage is responsible for $25 \%$ of the estimated 358,000 maternal deaths worldwide ${ }^{23}$.

This study shows that most of the recipients were blood group O rhesus positive $(67.4 \%)$ followed by blood group A positive(17.4\%). This follows the normal pattern and frequency of ABO blood gene distribution among Nigerians ${ }^{24,25}$.

Our study also showed that most of the transfusion reactions $(58.7 \%)$ took place during the blood transfusions at night. We have been able to demonstrate in this part of Nigeria that most of the transfusion adverse reactions occur at night. This further supports the 05/11/2006 Afssaps' decision on good transfusion practices that blood transfusions should be avoided at night unless in serious emergencies such as the patient is actively bleeding or has some other urgent clinical need. ${ }^{26}$ Why do adverse transfusion reactions occur more at night transfusions? This calls for further studies to ascertain the reason(s) blood recipients react more adversely when transfused at night.

\section{Conclusion}

The incidence of adverse transfusion reactions is high when compared to similar studies. Most of the subjects in this study received whole blood and it is advised we encourage component blood transfusion. In addition, night and over-night transfusions were highly associated with adverse reactions and hence it is also advised that, except in emergencies, night transfusions should be discouraged. Further research work is advocated on the reason(s) transfusion reactions occur more during night/over-night blood transfusions. 
VI. Tables And Figures

Table 1. Age distribution of the subjects

\begin{tabular}{|l|l|l|}
\hline Age & Frequency & Percentage \\
\hline $0-5$ & 2 & 4.3 \\
$6-10$ & 1 & 2.3 \\
$11-15$ & 0 & 0 \\
$16-20$ & 1 & 2.2 \\
$21-25$ & 4 & 8.8 \\
$26-30$ & 4 & 8.8 \\
$31-35$ & 5 & 10.8 \\
$36-40$ & 7 & 15.1 \\
$41-45$ & 7 & 15.1 \\
$46-50$ & 5 & 10.8 \\
$51-55$ & 6 & 13.1 \\
$56-60$ & 1 & 2.2 \\
$61-65$ & 2 & 4.3 \\
$66-70$ & 1 & 2.2 \\
Total & $\mathbf{4 6}$ & $\mathbf{1 0 0}$ \\
\hline
\end{tabular}


Fig.1 Sex distribution

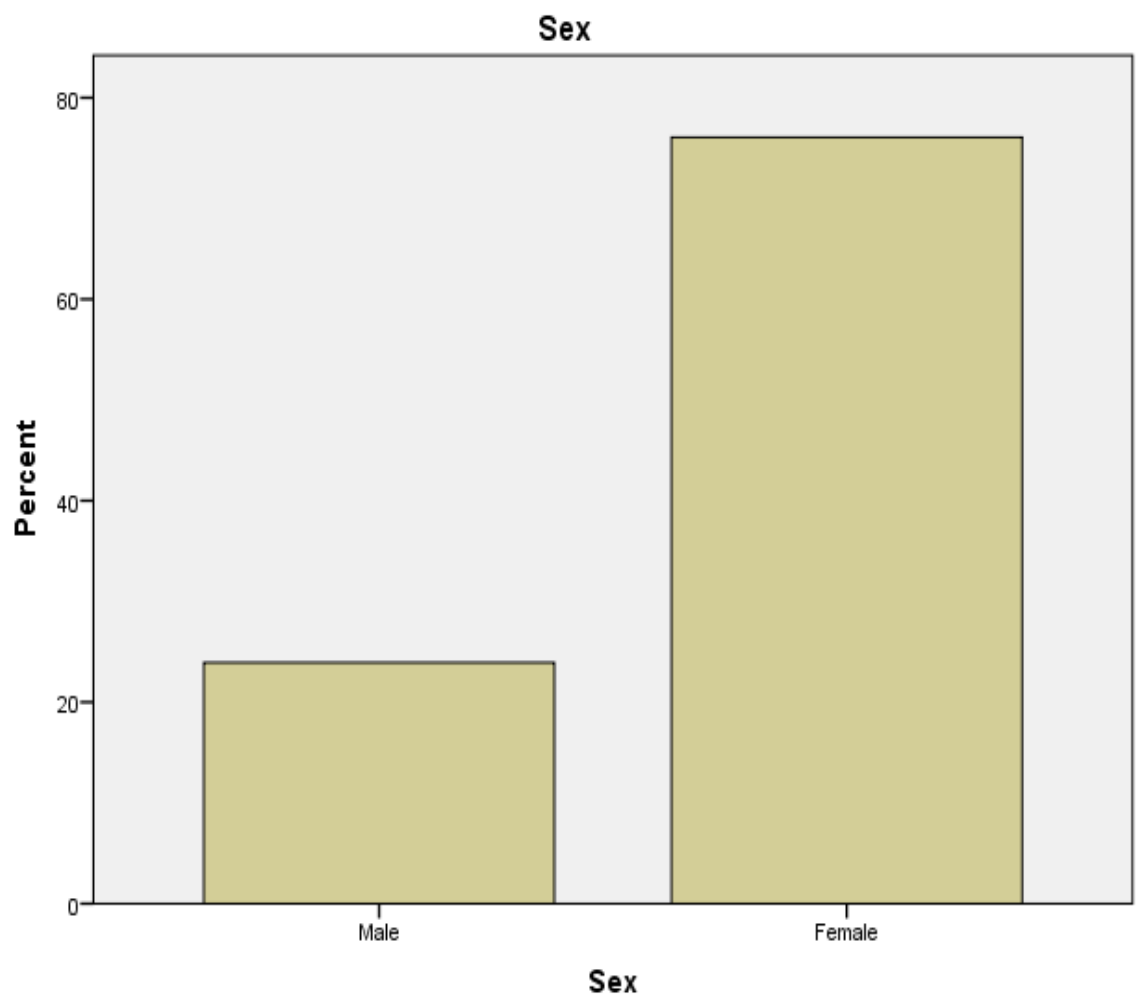

Fig.2 Blood component transfused

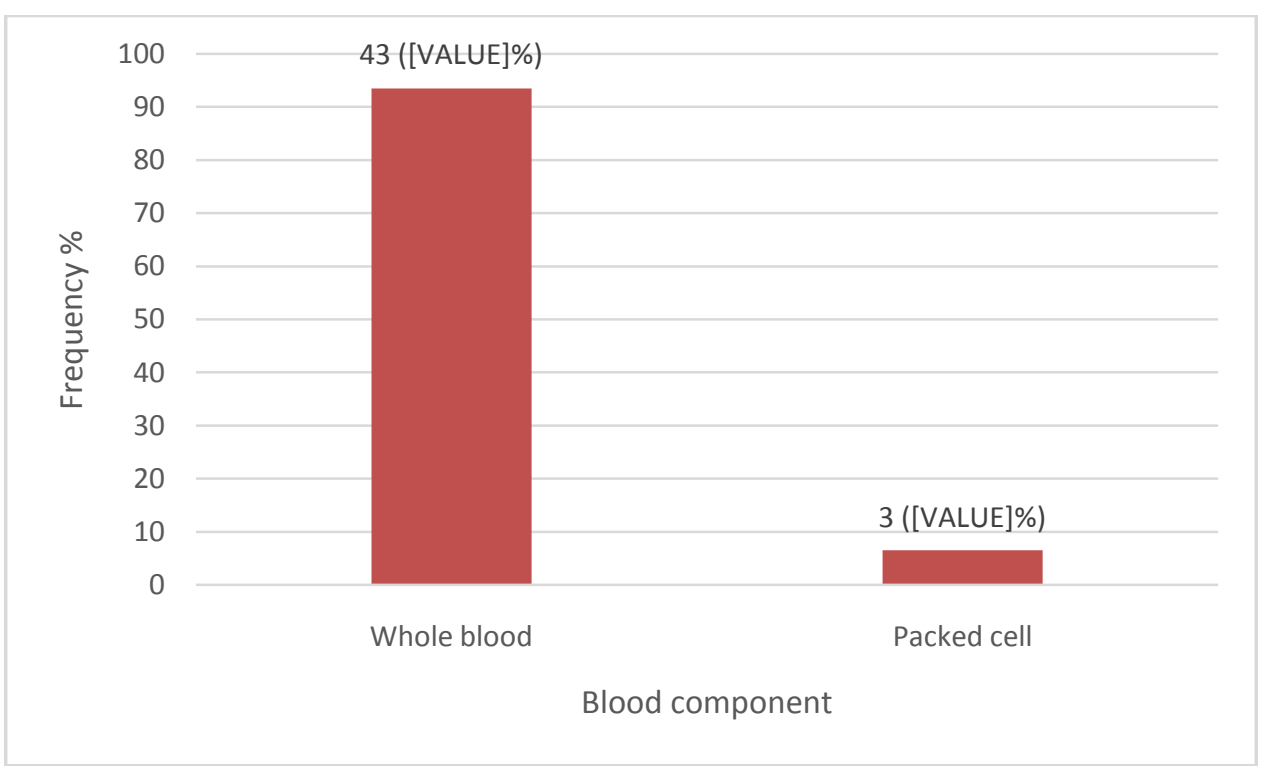


Table 2. Signs and Symptoms in the recipients

\begin{tabular}{|c|c|c|}
\hline Signs and syptoms & Frequency & Percentage \\
\hline \multicolumn{3}{|l|}{ Chills/ Rigors } \\
\hline Yes & 29 & 63.0 \\
\hline No & 17 & 37.0 \\
\hline Total & 46 & 100.0 \\
\hline \multicolumn{3}{|l|}{ Fever/Pyrexia } \\
\hline Yes & 27 & 58.7 \\
\hline No & 19 & 41.3 \\
\hline Total & 46 & 100.0 \\
\hline \multicolumn{3}{|l|}{ Itching/Urticaria } \\
\hline Yes & 14 & 30.4 \\
\hline No & 32 & 69.6 \\
\hline Total & 46 & 100.0 \\
\hline \multicolumn{3}{|l|}{ Nausea/Vomiting } \\
\hline Yes & 9 & 19.6 \\
\hline No & 37 & 80.4 \\
\hline Total & 46 & 100.0 \\
\hline \multicolumn{3}{|l|}{ Pain at infusion site } \\
\hline Yes & 5 & 10.9 \\
\hline No & 41 & 89.1 \\
\hline Total & 46 & 100.0 \\
\hline \multicolumn{3}{|l|}{ Back pains } \\
\hline Yes & 4 & 8.7 \\
\hline No & 42 & 81.3 \\
\hline Total & 46 & 100.0 \\
\hline \multicolumn{3}{|l|}{ Chest pains } \\
\hline Yes & 3 & 6.5 \\
\hline No & 43 & 93.5 \\
\hline Total & 46 & 100.0 \\
\hline \multicolumn{3}{|l|}{ Hypotension } \\
\hline Yes & 3 & 6.5 \\
\hline No & 43 & 93.5 \\
\hline Total & 46 & 100.0 \\
\hline \multicolumn{3}{|l|}{ Tachypnea } \\
\hline Yes & 2 & 4.3 \\
\hline No & 44 & 95.7 \\
\hline Total & 46 & 100.0 \\
\hline \multicolumn{3}{|l|}{ Tachycardia } \\
\hline Yes & 1 & 2.2 \\
\hline No & 45 & 97.8 \\
\hline Total & 46 & 100.0 \\
\hline
\end{tabular}

Table 3. Transfusion reaction from various wards

\begin{tabular}{|l|l|l|l|}
\hline \multicolumn{2}{|c|}{ Ward/department } & Frequency & \\
\hline \multirow{4}{*}{} & A and E & 3 & 6.5 \\
\cline { 2 - 4 } & Int Medicine & 8 & 17.4 \\
\cline { 2 - 4 } & O and G & 21 & 45.7 \\
\cline { 2 - 4 } & Paediatrics & 4 & 8.7 \\
\cline { 2 - 4 } & Surgery & 10 & 21.7 \\
\cline { 2 - 4 } & Total & 46 & 100.0 \\
\hline
\end{tabular}


Signs And Symptoms Of Reported Cases Of Transfusion Reactions In A Rural ....

\begin{tabular}{|c|l|l|l|}
\hline \multicolumn{3}{|c|}{ Table 4. Blood group of recipients } \\
\hline \multicolumn{2}{|c|}{ Blood Group } & Frequency & \\
\hline \multirow{4}{*}{} & Opos & 31 & 67.4 \\
\cline { 2 - 4 } & Oneg & 2 & 4.3 \\
\cline { 2 - 4 } & Apos & 8 & 17.4 \\
\cline { 2 - 4 } & Bpos & 1 & 2.2 \\
\cline { 2 - 4 } & Bneg & 2 & 4.3 \\
\cline { 2 - 4 } & ABpos & 2 & 4.3 \\
& & \\
\cline { 2 - 4 } & Total & 46 & 100.0 \\
\hline
\end{tabular}

\begin{tabular}{|l|l|l|l|}
\hline \multicolumn{2}{|c|}{ Table 5. Day/Time of transfusion } \\
\hline \multicolumn{2}{|c|}{ Day/time } & Frequency & Percent \\
\hline \multirow{3}{*}{} & Morning & 12 & 26.1 \\
\cline { 2 - 4 } & $\begin{array}{l}\text { Afternoo } \\
\mathrm{n}\end{array}$ & 7 & 15.2 \\
\cline { 2 - 4 } & Night & 27 & 58.7 \\
\cline { 2 - 4 } & Total & 46 & 100.0 \\
\hline
\end{tabular}

\section{References}

[1]. Schmidt PJ, Leakock AG. Forgotten Transfusion history. BMJ 2002;323:2484-2487

[2]. Turgeon LM In fundamentals of Immunohematology theory and technique. Philadelphia USA. Lea and febigar(UK), 1989; 344366

[3]. Contreras M, Hewit PE. Clinical blood transfusion. In Hoffrand BA, Lewis MS, Tuttenham EGD(eds), Post graduate haematology, $4^{\text {th }}$ edition, oxford University press New York 2001, pp 215-299

[4]. Larison PJ and Cooke LM. The adverse effects on blood transfusion. In Harmening DM. Jaypee medical publishers modern blood banking and transfusion sevices $3^{\text {rd }}$ edition. Jaypee brothers new delhi:1998; pp361-370

[5]. Vamvacas EC, Pineda AA. Allergic and anaphylactic reactions. In Popovisky MA ed. Transfusion reactions $3^{\text {rd }}$ edition. Bethesda AABB Press

[6]. Ahmed SG, Kyario and Ibrahim VA. Urticarial reactions in Obstertics and Gyaecology transfusion in Maidugri, north east Nigeria. Niger Postgrad Med J 2002;137-139

[7]. Hoffbrand AV, Moss PAH. Essential Haematology, $6^{\text {th }}$ edition, Wiley-Blackwell publishing ltd (UK), 2011, pp 398-412.

[8]. Vander-Hart M, Engelfreit CP, Prins HK et al. a haemolytic transfusion reaction without demonstrable antibodies in vitro, Vox Sang, 1963; 8: 363-370.

[9]. Kissniyer Nidsen F, Jensen KB and Ersbak J. Severe haemolytic transfusion reactions caused by apparently compatible red cells. Br J Haematol, 1961; 7: 36-41

[10]. Domen RE: Adverse reactions associated with autologous blood transfusion, evaluation and incidence at a large academic hospital. Transfusion 1999; 38(3) 296-300

[11]. _Nyashadzaishe M, Star Khoza, David A. M, McLeod E. C, Maarten J. P, Marinus van Hulst._Incidence and pattern of 12 years of reported transfusion adverse events in Zimbabwe: a retrospective analysis. Blood Transfusion 2014; 12: 362-367

[12]. Arewa OP, Akinola NO, Salawau L. Blood transfusion reactions, evaluation of 462 transfusions at a tertiary hospital in Nigeria. Afr J Med Sci 2009; 38:143-148

[13]. Baron JF. The Haemovigilance Network: the French experience. In building a blood system for the $21^{\text {st }}$ century, proceedings and recommendations, Houston P(ed) November, 1997, 37-39.

[14]. Climent_Peris C and Velez-Rosario R. Immediate transfusion reactions. PR Health Sci J 2001; 20: 229-235.

[15]. South Africa National Blood Service. Haemovigilance Report 2007: South Africa National Blood Service; 2007.

[16]. Baibergenova A, Thabane L, Akhtar-Danesh N, Levine M, Gafni A.Sex differences in hospital admissions from emergency departments in asthmatic adults: a population-based study. Ann Allergy Asthma Immunol. 2006;96(5):666-672.

[17]. Norma BL, Majed AR, Neil Blumberg. Red cell transfusion. In Kenneth K, Marshal AL, Ernest B, Thomas JK, Uri Seligsohn, Josef TP (eds). Williams Hematology $8^{\text {th }}$ edition McGraw Hill China 2010, pp 2297-2300

[18]. Hoxworth P, Skinner C. improvement in blood transfusion service III; results of 3077 transfusion of bank blood; a statistical analysis. ArchSurg; 1941; 42: 498-507

[19]. Heddle NM, Klama LN and Griffith LA. Prospective study to identify the risk factors associated with acute reactions to platelets and red cell transfusion. Transfusion 1993; 33: 794-797

[20]. Heddle NM, Klama LN and Griffith LA et al. the role of plasma from platelet concentrates in transfusion reactions. N Eng J Med 1994; 331:625-628

[21]. Seldon TH. Management of blood transfusion reactions. Med Clin North Am 1956; 1217-1224.

[22]. www.medscape.com/viewarticle(assessed July 30 $0^{\text {th }} 2016$ )

[23]. McLintock C, James AH. Obstetric hemorrhage. J thromb Haemost 2011; 9(8):1441-51.

[24]. Omotade OO, Adeyemo AA, Kayode CM, Falade SL, Ikpeme S. Gene frequencies of ABO and Rh (D) blood group alleles in a healthy infant population in Ibadan, Nigeria. West Afr J Med 1999; 18(4): 294-297

[25]. Falusi AG, Ademowo OG, Latunji CA, Okeke AC, Olatunji PO, Onyekwere TO, Jimmy EO, Raji Y, Hedo CC, Otukonyong EE, Itata EO. Distribution of ABO and RH genes in Nigeria. Afr J Med Sci 2000; 29(1):23-26

[26]. Roche C, Théfenne H, Hance P, Garnotel E. Blood transfusion practices: about transfusions at night Transfus Clin Biol. 2013; 20(56):496-501. 